\title{
PRVI NALAZ PARAZITODA (Platygaster robiniae) NA BAGREMOVOJ MUHI ŠIŠKARICI U BOSNI I HERCEGOVINI
}

\author{
FIRST RECORD OF PARASITOD (Platygaster robiniae) \\ ON BLACK LOCUST GALL MIDGE IN BOSNIA AND \\ HERZEGOVINA
}

\author{
Kenan ZAHIROVIĆ* , Osman MUJEZINOVIĆ ** , Mirza DAUTBAŠIĆ
}

\begin{abstract}
SAŽETAK
Bagrem je alohtona vrsta drveća, koja je na naše prostore unesena i prije 400 godina. Iako je invazivna vrsta Obolodiplosis robiniae na ovim prostorima prvi put utvrđena 2007. godine, na stablima bagrema do sada nisu primijećene značajne štete. U mjesecu lipnju 2018. godine utvrđen je prvi nalaz parazitoida bagremove muhe šiškarice (Platygaster robiniae), iako se vjerojatno puno ranije javio, međutim, do sada nije opisan i predstavlja novu vrstu u entomološkom kompleksu na području Bosne i Hercegovine.
\end{abstract}

KLJUČNE RIJEČI: bagremova muha šiškarica, parazitoid, Hymenoptera, Platygastridae.

\section{UVOD}

\section{INTRODUCTION}

Bagrem je alohtona vrsta koja je introducirana s područja Sjeverne Amerike. Značajan je posebno u pčelarstvu, jer je sama vrsta medonosna i najčešće se sadi u blizini naselja i služi za pašu pčela. Posebno je značajan kao brzorastuća vrsta, malih ekoloških zahtjeva, te se vrlo često koristi kao vrsta za sanaciju klizišta. Bagremova muha šiškarica (Obolodiplosis robiniae Haldeman) je prvi puta utvrđena na području Europe 2003. godine (Italija). Skuhrava i sur. (2007) su istu utvrdili na području Bosne i Hercegovine četiri godine kasnije. Pernek i Matošević (2009) su utvrdili parazitoida Platygaster robiniae Buhl \&
Duso (Hymenoptera, Platygastridae) na ovoj invazivnoj vrsti na području Hrvatske, te drugi autori u drugim državama (Wermelinger i Skuhravá, 2007; Buhl i Duso, 2008; János Bálint i sur., 2010; Tóth i sur., 2011; Bella, 2014; Mieczkowska i Ambroziak, 2016; Buhl i Jałoszyński, 2018). P. robiniae svoj ciklus razvoja od jajeta do imaga završava za 28 dana (Kim i sur., 2011). Iako, na području Bosne i Hercegovine prisutnost parazitoida P. robiniae nije da sada opisana, on se vjerojatno puno ranije javio, jer je isti ranije utvrđen na području Hrvatske. Cilj ovoga rada je bilo utvrđivanje prisutnosti parazitoida bagremove muhe šiškarice morfološkim putem na istraživanim lokalitetima i postotka parazitiranosti ličinki bagremove muhe šiškarice.

\footnotetext{
* Dr. sc. Kenan Zahirović, JP Šumsko-privredno društvo Zeničko-dobojskog kantona d.o.o Zavidovići, Alije Izetbegovića 25, 72220 Zavidovići, Bosna i Hercegovina, e-mail: zahirovic_kenan@yahoo.com

** Prof. dr. sc. Osman Mujezinović, Šumarski fakultet Univerziteta u Sarajevu, Katedra za zaštitu šuma, urbanog zelenila i lovnog gospodarenja, Zagrebačka 20, 71000 Sarajevo, Bosna i Hercegovina, e-mail: osmansfs@yahoo.com

2 prof. dr. sc. Mirza Dautbašić, Šumarski fakultet Univerziteta u Sarajevu, Katedra za zaštitu šuma, urbanog zelenila i lovnog gospodarenja, Zagrebačka 20, 71000 Sarajevo, Bosna i Hercegovina, e-mail: mirzad@bih.net.ba
} 


\section{MATERIJAL I METODE MATERIALS AND METHODS}

Pregledom terena u lipnju 2018. godine u Bosni i Hercegovini na stablima bagrema (Robinia pseudoacacia L.) primijećene su šiške izazvane štetnikom $O$. robiniae. Detaljnim pregledom šiški utvrđene su ličinke i kokoni ove invazivne vrste, te prisutnost parazitoida $P$. robiniae (parazitirane ličinke i kokoni). Istraživanja su provedena na ukupno četiri općine/lokaliteta na području centralne Bosne (tablica 1). Ukupno je prikupljeno 118 palistića bagrema. Uzorci ličinki i kokona bagremove muhe šiškarice i parazitoida su sakupljeni i pohranjeni u 75\% etanol, radi kasnijih morfoloških analiza. Razvojni stadijumi insekta su fotografirani prenosnim mikroskopom SVP DM540 i digitalnim fotoaparatom. Utvrđivana je parazitiranost ličinki bagremove muhe šiškarice na svim lokalitetima, te prosječan broj šiški po palistiću bagrema i ličinki po šiški. Ovim istraživanjem nije proučavana biologija ovih vrsta.

\section{REZULTATI}

\section{RESULTS}

Parazitoid bagremove muhe šiškarice je prvi put otkriven u Bosni i Hercegovini 12.6.2018. godine na području općine Tešanj. Iz 120 prikupljenih palistića bagrema, na 78 palistića bagrema utvrđeni su razvojni stadiji bagremove muhe šiškarice ili prisutnost parazitoida $(65 \%)$. Uz postotak parazitiranosti utvrđivan je i prosječan broj šiški po palistiću bagrema i ličinki po šiški (tablica 2).

Tablica 1. Nalazi bagremove muhe šiškarice i parazitoida $P$. robiniae u Bosni i Hercegovini

Table 1. Records of blacklocust gall midge and parasitoid P. robiniae in Bosnia and Herzegovina

$\begin{array}{ccc}\text { Datum - Date } & \text { Lokalitet - Locality } & \text { Koordinate - Coordinates } \\ \text { 12.06.2018. } & \text { Tešanj } & 44^{\circ} 35^{\prime} 1 " \mathrm{~N} ; 17^{\circ} 57^{\prime} 35^{\prime \prime} \mathrm{E} \\ 13.06 .2018 . & \text { Breza } & 44^{\circ} 1^{\prime} 34^{\prime \prime} \mathrm{N} ; 18^{\circ} 16^{\prime} 54^{\prime \prime} \mathrm{E} \\ 15.06 .2018 . & \text { Visoko } & 44^{\circ} 0^{\prime} 48^{\prime \prime} \mathrm{N} ; 18^{\circ} 5^{\prime} 27^{\prime \prime} \mathrm{E} \\ 13.06 .2018 . & \text { Vareš } & 44^{\circ} 9^{\prime} 18^{\prime \prime} \mathrm{N} ; 18^{\circ} 19^{\prime} 19^{\prime \prime} \mathrm{E}\end{array}$

\section{DISKUSIJA I ZAKLJUČCI DISCUSSION AND CONCLUSIONS}

Bagremova muha šiškarica je najvjerojatnije na područje Europe unesena sadnim materijalom (Pernek i Matošević, 2009). U šiškama koje je izazvala bagremova muha šiškarica na svim ispitivanim lokalitetima u Bosni i Hercegovini, utvrđena je i prisutnost parazitoida Platygaster robiniae. Iako se radi o malom broju parazitiranih ličinki u šiškama, značajna je prisutnost ovog insekta u entomološkom kompleksu Bosne i Hercegovine, jer umanjuje brojnost populacije bagremove muhe šiškarice. Prema Pernek i Matošević (2009) utvrđeno je da ako je postotak parazitiranosti ličinki mali, to je pokazatelj da je populacija bagremove muhe šiškarice umanjena. Kako je na palistićima bagrema pronađen velik broj praznih šiški, može se zaključiti da ličinke koje su pronađene u šiškama pripadaju drugoj generaciji, posebice jer je na području općine Vareš pronađen kokon bagremove muhe šiškarice iz prve generacije. Općina Vareš se nalazi na $850 \mathrm{~m}$ nadmorske visine, te je od svih istraživanih lokaliteta na najvećoj nadmorskoj visini, gdje se snijeg dugo zadržava, pa stoga i ne treba čuditi kašnjenje i u razvoju ovog štetnika. Utvrđivan je prosječan broj šiški po palistićima bagrema i broja ličinki u šiškama te njihova parazitiranost. Slične rezultate su dobili i drugi autori (Mihajlović i sur., 2008; Pernek i Matošević, 2009). Tóth i sur. (2011) su u svojim istraživanjima utvrdili da parazitiranost ličinki može ići čak i preko $40 \%$.

$\mathrm{Na}$ osnovi provedenih istraživanja može se zaključiti sljedeće:

- Bagremova muha šiškarica (Obolodiplosis robiniae) utvrđena je na svim lokalitetima istraživanja, te ju je lako uočiti na terenu;

- Prosječan broj šiški po palistiću bagrema kretao se od 1,04 do 1,48 ;

- Prosječan broj ličinki po šiški kretao se od 0,42 do 0,77 ;

- Utvrđen je prvi nalaz parazitoida Platygaster robiniae, koji ujedno predstavlja novu vrstu u entomološkom kompleksu Bosne i Hercegovine;

- Parazitiranost ličinki bagremove muhe šiškarice iznosila je od 6,66 do $14,28 \%$.

Tablica 2. Prosječan broj šiški po palistiću bagrema i ličinki po šiški i parazitiranost bagremove muhe šiškarice po lokalitetima u Bosni i Hercegovini Table 2. Average number of galls and larvae on acacia leaflet and parasitism of black locust gall midge on different localities in Bosnia and Herzegovina

\begin{tabular}{cccc} 
Lokalitet / & $\begin{array}{c}\text { Prosječan broj šiški po palistiću / } \\
\text { Locality }\end{array}$ & $\begin{array}{c}\text { Prosječan broj ličinki po šiški / } \\
\text { Average number of larvae in galls }\end{array}$ & $\begin{array}{c}\text { Postotak parazitiranosti / } \\
\text { Percentage of parastitism }\end{array}$ \\
\hline Tešanj & $1,44 \pm 0,67$ & $0,51 \pm 0,67$ & 9,52 \\
Breza & $1,21 \pm 0,49$ & $0,42 \pm 0,50$ & 8,33 \\
Visoko & $1,48 \pm 0,70$ & $0,77 \pm 1,05$ & 14,28 \\
Vareš & $1,04 \pm 0,20$ & $0,65 \pm 0,48$ & 6,66 \\
Ukupno/Total & $1,32 \pm 0,59$ & $0,57 \pm 0,71$ & 10,14
\end{tabular}



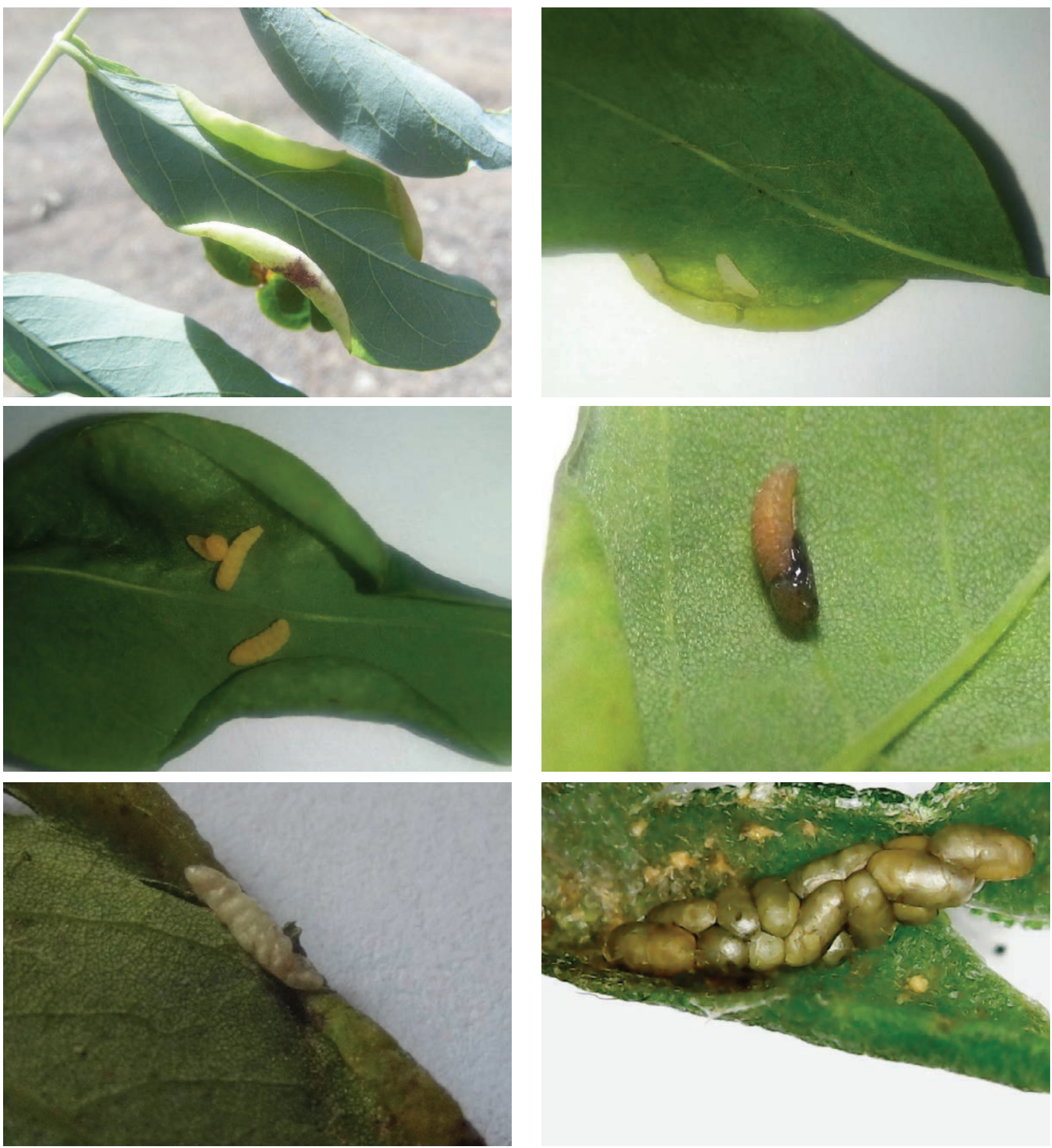

Slika 1, 2, 3, 4, 5 i 6. Šiške na palistićima bagrema; bijele ličinke; žute ličinke; kokon bagremove muhe šiškarice; parazitirana ličinka i kokoni parazitoida $P$. robiniae

Picture 1, 2, 3, 4, 5 and 6 . Galls on acacia leaflet; white larvae; yellow larvae; coccon of black locust gall midge; parasitised larvae; and coccons of parasitoid P. robiniae

\section{LITERATURA}

\section{REFERENCES}

- Bálint, J., P. Neacșu, B. Adalbert, J. Fail, G. Vétek, 2010: First record of the black locust gall midge, Obolodiplosis robiniae (Haldeman) (Diptera: Cecidomyiidae), in Romania. North-Western Journal of Zoology. 6. 319-322.
- Bella, S., 2014: Invasive insect pests and their associated parasitoids on ornamental urban plants on Corfu island - Phytoliriomyza jacarandae Steyskal and Spencer 1978 (Diptera, Agromyzidae) a new record in Greece. Hellenic Plant Protection Journal 7(2): 53-59.

- Buhl, P.N., C. Duso, 2008: Platygaster robiniae n. sp. (Hymenoptera: Platygastridae) Parasitoid of Obolodiplosis robiniae (Dip- 
tera: Cecidomyiidae) in Europe. Systematics Vol. 101, No. 2. str. 297-300

- Buhl, P.N., P. Jałoszyński, 2018: Twenty three species of Platygastrinae (Hymenoptera: Platygastridae) new to the fauna of Poland. Acta entomologica silesiana. Vol. 26: 1-7.

- Kim, I.-K., J.-D. Park, S.-C. Shin, I.-K. Park, 2011: Prolonged embryonic stage and synchronized life-history of Platygaster robiniae (Hymenoptera: Platygastridae), a parasitoid of Obolodiplosis robiniae (Diptera: Cecidomyiidae). Biological Control - Biol. Control. 57. pp. 24-30.

- Mieczkowska, A.N., A.K. Ambroziak, 2016: Pryszczarek robiniowy Obolodiplosis robiniae (Haldeman, 1847) (Diptera: Cecidomyiidae) - gatunek obcy w faunie Polski. Konferencja pt. „Odnawialne źródła energii i ochrona przyrody wdziałalności studenckich kół naukowych”. pp. 1.

- Mihajlović, LJ., M. Glavendekić, I. Jakovljević, S. Marjanović, 2008: Obolodiplosis robiniae (Haldeman) (Diptera: Cecidomyi- idae) - nova štetočina bagrema u Srbiji. Glasnik Šumarskog fakulteta, 97: 197-208.

- Pernek, M., D. Matošević, 2009: Bagremova muha šiškarica (Obolodiplosis robiniae) - novi štetnik bagrema i prvi nalaz parazitoida Platygaster robiniae u Hrvatskoj. Šumarski list br. 3-4. str. 157-163.

- Skuhravá, M., V. Skuhravý, G. Csoka, 2007: The invasive spread of the gall midge Obolodiplosis robiniae in Europe. Cecidology, Vol. 22, No 2, 84-87.

- Tóth, P., M. Váňová, J. Lukáš, 2011: Impact of natural enemies on Obolodiplosis robiniae invasion. Biologia. 66. 870-876.

- Wermelinger, B., M. Skuhravá, 2007: First records of the gall midge Obolodiplosis robiniae (Haldeman) (Diptera: Cecidomyiidae) and its associated parasitoid Platygaster robiniae Buhl \& Duso (Hymenoptera: Platygastridae) in Switzerland. Mitteilungen der Schweizerischen Entomologischen Gesellschaftbulletin de la Societe Entomologique Suisse 80. 217-221.

\section{SUMMARY}

Acacia is an allochthonous tree species that has been introduced into our region 400 years ago. Although the invasive species of Obolodiplosis robiniae in this region was first determined in 2007, significant damages have not been recorded on the acacia trees. Average number of galls on black locust leaflet were from 1,04 to 1,48 . Average number of larvae in galls were from 0,42 to 0,77 . In June of 2018, the first record of a parasitoid of black locust gall midge (Platygaster robiniae) was determined, although it is likely that was occured earlier, but this is the first record and represents a new species in the entomological complex in the territory of Bosnia and Herzegovina. Parasitism of larvae of Obolodiplosis robiniae were from 6,66 to $14,28 \%$ on different localities.

KEY WORDS: black locust gall midge, parasitoid, Hymenoptera, Platygastridae. 